\title{
ATROPINE AND THE ELECTRICAL ACTIVITY OF THE HEART DURING INDUCTION OF ANAESTHESIA IN CHILDREN
}

\author{
J. SAgarminaga, M.D., AND J. E. Wyinands, M.D. ${ }^{*}$
}

THE ROLE OF PREMEDICATION in the incidence and severity of cardiac arrhythmias during induction of anaesthesia has received little attention. Although many authors ${ }^{1-18}$ have made recommendations regarding premedication and its value in the prevention of arrhythmias, only a few $w^{3-6,10,14,17,18}$ have attempted to study this problem systematically.

The aetiology of cardiac arrhythmias and catastrophes during induction and maintenance of anaesthesia has been studied extensively ${ }^{19-54}$ sitice John Snow ${ }^{19}$ first reported in 1858 on cardiac arrest occurring during induction of anaesthesia with chloroform. Following this first report, the relative importance of the sympathetic and parasympathetic nervous systems has been the subject of numerous investigations. Many authors ${ }^{2,6,8,9,11,15,18,20,44,46}$ have pointed to the role of the parasympathetic system in the aetiology of these arrhythmias. On the other hand, other authors ${ }^{4,5}, 19,17,21-24,35,38-43$ starting with the first reports by Levy ${ }^{23}$ have attributed the disturbances in cardiac rhythm to increased activity of the sympathetic nervous system. The effects of other factors, such as hypoxia, hypercarbia, acidosis, and sensitization of the myocardium to circulating catecholamines have also received considerable attention. ${ }^{4,5,12,28,30-34,38,41,44,46,48-77}$

Earlier studies were mainly concerned with arrhythmias occurring during chloroform, cyclopropane, and trichloroethylene anaesthesia. ${ }^{50,52}$ These arrhythmias have been adequately documented.

The exact disturbances in electrical activity of the heart produced by parasympathetic and sympathetic stimulation have been thoroughly investigated and reported. ${ }^{55-77}$ The pharmacology, advantages, and possible dangers of the administration of atropine have also been well studied.18,18,78-85

With this background we decided to do a systematic study of the electrical activity of the heart during induction of anaesthesia in children. We wished to determine the incidence and aetiology of cardiac irregularities when anaesthesia was induced by the techniques commonly used in our hospital. The possibility of preventing or abolishing these arrhythmias naturally followed the completion of the primary purpose of the paper.

\section{Material aNd METHódS}

One hundred and seventy-five inductions of anaesthesia in children under ten years of age were studied by means of a continuous-recording, standard Lead II of the electrocardiogram. A recording was taken continuously from immediately prior to induction until the child was being ventilated following endotracheal intubation. The sedative effect of the premedication permitted the application

"Department of Anaesthesia, Royal Victoria Hospital, Montreal, Quebec. 
of the electrocardiographic electrodes prior to induction in all but 11 cases. These 11 . children were given pentothal rectally and the electrocardiographic recording commenced after they were asleep. The method allowed us to compare the E.C.G. of the awake premedicated child and the changes brought about by our anaesthetic agents and techniques. During the induction, any alteration in agent or technique was carefully marked on the tracing so that the relation between the events and the E.C.G. could be determined. There was no selection as to anaesthetist, anaesthetic agent, or technique and the patients were grouped according to premedication and drugs.

The rate was obtained from the electrocardiographic tracings by measuring the R-R interval every 15 seconds and charted for each patient. Arrhythmias were also ǹoted.

The patients were divided into five series. Series I. (Table I) consisted of 50 patients. Premedication was with nembutal, morphine or demerol, and hyoscine. The dose of hyoscine employed was $0.01 \mathrm{mg} . / \mathrm{kg}$.

Series II (Table II) consisted of 50 patients. Premedication was with nembutal, morphine or demerol, and hyascine as in Series I. However, atropine (0.01 mg./ $\mathrm{kg}$.) was given intravenously sometime during the induction prior to the administration of succinycholine and/or intubation.

Series III, IV, and V (Tables III, IV, and V respectively) consisted of 25 cases each. Premedication was with nembutal, and morphine or demerol. Atropine was substituted for hyoscine and the dosage was $0.01,0.02$, and $0.03 \mathrm{mg} . / \mathrm{kg}$. respectively.

Age, sex, and weight factors were statistically comparable in the five series. In all cases, the nembutal, morphine, and demerol in the premedication were given according to the dose schedule recommended by Leigh and Belton. ${ }^{7}$

As can be seen from the tables, numerous agents were used but the main division was into those patients who did or did not receive succinyleholine.

In the majority of cases (102) induction was with high flows of nitrous oxide and oxygen with the Magill circuit and when the child became drowsy halothane was added. Once asleep, ether was introduced into the circut and halothane was gradually withdrawn while the concentration of ether was increased. In 147 cases succinylcholine was given intravenously ( $1.0 \mathrm{mg} . / \mathrm{kg}$.) sometime during the induction to facilitate intubation. Because anaesthesia was usually for tonsillectomy the larynx was not sprayed with a local anaesthetic. Variation in this basic technique involved in most cases the use of intravenous pentothal in older children and rectal pentothal when the child was un-co-operative. In other cases the children were intubated in deep general anaesthesia without the use of succinylcholine. The number of cases done by each technique can be seen in the tables pertaining to each series.

\section{RESULTS}

The results are tabulated in Tables I to $\mathrm{V}$.

In Series I (Table I) 40 patients, or 80 per cent, had cardiac arrhythmias. Because the arrhythmias encountered were of vagal origin (Figs. $3-5,7$ ) we then 
TABLE I

First Series. Premedication with Hyoscine (0.01 mg. $/ \mathrm{kg}$.)

\begin{tabular}{lrr}
\hline \multicolumn{1}{c}{ Technique } & No. of cases & Arrhythmias \\
\hline I. Succinylcholine & 1 & 1 \\
A. Rectal pentothal & 11 & 5 \\
B. I. V. pentothal & 14 & 13 \\
C. Induction with gases & 3 & 3 \\
1. $\mathrm{N}_{2} \mathrm{O}$, fluothane, and ether & 2 & 1 \\
2. $\mathrm{N}_{2} \mathrm{O}$ and fluothane & 1 & 1 \\
3. Cyclopropane, $\mathrm{N}_{2} \mathrm{O}$, fluothane, and & 1 & 1 \\
4. Cyclor & & \\
5. Cyclopropane, $\mathrm{N}_{2} \mathrm{O}$, and fluothane & 1 & 1 \\
II. No succinylcholine & 4 & 2 \\
A. Rectal pentothal & 12 & 12 \\
B. Knight's solution & \\
C. Induction with gases & & \\
1. $\mathrm{N}_{2} \mathrm{O}$, fluothane, and ether & 50 & $40(80 \%)$ \\
Totals & &
\end{tabular}

TABLE II

Second Serres. Premedication with Hyoscine $(0.01 \mathrm{mg} . / \mathrm{kg}$. $)$, Intravenous ATROPINE $(0.01 \mathrm{mg} . / \mathrm{kg}$.) BEFORE SUCCINYLCHOLINE AND $/$ OR INTUBATION

\begin{tabular}{|c|c|c|c|}
\hline \multirow[b]{2}{*}{ Technique } & \multirow[b]{2}{*}{ No. of cases } & \multicolumn{2}{|c|}{ Arrhythmias } \\
\hline & & $\begin{array}{c}\text { Before } \\
\text { atropine } \\
\end{array}$ & $\begin{array}{c}\text { After } \\
\text { atropine }\end{array}$ \\
\hline $\begin{array}{l}\text { I. Succinylcholine } \\
\text { A. Rectal pentothal } \\
\text { B. I.V. pentothal } \\
\text { C. Induction with gases } \\
\text { 1. } \mathrm{N}_{2} \mathrm{O} \text {, fluothane, and ether } \\
\text { 2. } \mathrm{N}_{2} \mathrm{O} \text { and fluothane } \\
\text { 3. Cyclopropane, } \mathrm{N}_{2} \mathrm{O} \text {, fluothane, } \\
\text { and ether } \\
\text { 4. Cyclopropane, } \mathrm{N}_{2} \mathrm{O} \text {, and fluothane }\end{array}$ & $\begin{array}{r}2 \\
8 \\
26 \\
6 \\
1 \\
1\end{array}$ & $\begin{array}{r}0 \\
2 \\
22 \\
5\end{array}$ & $\begin{array}{l}0 \\
0 \\
1 \\
1 \\
0 \\
0\end{array}$ \\
\hline $\begin{array}{l}\text { 11. No succinylcholine } \\
\text { C. Induction with gases } \\
\text { 1. } \mathrm{NO}_{2} \text { fluothane, and ether }\end{array}$ & 6 & 4 & 0 \\
\hline Totals & 50 & $\begin{array}{c}35 \\
(70 \%)\end{array}$ & $\stackrel{2}{(4 \%)}$ \\
\hline
\end{tabular}

TABLE III

Third Series. Premedication with Atropine (0.01 mg. $/ \mathrm{kg}$.)

\begin{tabular}{lcc}
\hline \multicolumn{1}{c}{ Technique } & No. of cases & Arrhythmias \\
\hline I. Succinylcholine & 1 & 1 \\
A. Rectal pentothal & 6 & 4 \\
B. I.V. pentothal & 14 & 12 \\
C. Induction with gases & 1 & 1 \\
1. $\mathrm{N}_{2} \mathrm{O}$, fluothane, and ether & 1 & 1 \\
2. $\mathrm{N}_{2} \mathrm{O}$ and fluothane & & \\
3. Cyclopropane, $\mathrm{N}_{2} \mathrm{O}$, fluothane, and ether & 1 & 1 \\
II. No succinylcholine & 2 & $20(80 \%)$ \\
C. Induction with gases \\
1. $\mathrm{N}_{2} \mathrm{O}$, fluothane, and ether
\end{tabular}


TABLE IV

Fourth Series. Premedication with Atropine $(0.02 \mathrm{mg} . / \mathrm{kg}$.

\begin{tabular}{lcc}
\hline \multicolumn{1}{c}{ Technique } & No. of cases & Arrhythmias \\
\hline I. Succinylcholine & 2 & 2 \\
A. Rectal pentothal & 5 & 0 \\
B. I. V. pentothal & 9 & 6 \\
C. Induction with gases & 2 & 2 \\
1. $\mathrm{N}_{2} \mathrm{O}$, fluothane, and ether & 1 & 1 \\
2. Cy and fluothane & 1 & 1 \\
3. Cyclopropane, $\mathrm{N}_{2} \mathrm{O}$, fluothane, and ether & & \\
4. Cyclopropane, $\mathrm{N}_{2} \mathrm{O}$, and fluothane & & 2 \\
II. No Succinylcholine & 5 & $14(56 \%)$. Induction with gases \\
1. $\mathrm{N}_{2} \mathrm{O}$, fluothane, and ether & 25 & 14 \\
Totals
\end{tabular}

TABLE V

Fifth Series. Premedication with Atropine ( $0.03 \mathrm{mg} . / \mathrm{kg}$.

\begin{tabular}{lcc}
\hline \multicolumn{1}{c}{ Technique } & No. of cases Arrhythmias \\
\hline I. Succinylcholine & 1 & 1 \\
A. Rectal pentothal & 4 & 2 \\
B. I. $\mathrm{V}$. pentothal & 8 & 5 \\
C. Induction with gases & 2 & 1 \\
$\quad$ 1. $\mathrm{N}_{2} \mathrm{O}$, fluothane, and ether & 1 & 1 \\
2. $\mathrm{N}_{2} \mathrm{O}$ and fluothiane & & \\
3. Cyclopropane, $\mathrm{N}_{2} \mathrm{O}$, fluothane, and ether & & 0 \\
II. No succinylcholine & 2 & 2 \\
A. Rectal pentothal & 6 & 0 \\
C. Induction with gases & 1 & $12(48 \%)$ \\
$\quad$ 2. $\mathrm{N}_{2} \mathrm{O}$, fluothane, and ether & 25 & 12 and fluothane
\end{tabular}

studied 50 patients premedicated as in the first series but to whom atropine ( 0.01 $\mathrm{mg} . / \mathrm{kg}$.) was administered intravenously sometime during induction prior to the administration of succinylcholine and/or intubation. The results are tabulated in Table II. Prior to the intravenous administration of atropine 35 patients, or 70 per cent, had cardiac arrhythmias. After the administration of atropine intravenously only 2 patients, or 4 per cent, had residual disturbances in the electrical activity of the heart (Fig. 2). The intravenous administration of atropine caused transient, minor increase in vagal activity in 7 out of the $=50$ patients (Fig. 6). In the 2 cases in which atropine did not completely abolish the pre-existing disturbance of rhythm it did nevertheless decrease the severity. In all other cases, the subsequent injection of succinylcholine and the manœuvres of intubation significantly failed to alter the established sinus tachycardia.

Intravenous atropine was so effective in abolishing and preventing disturbances of electrical activity of the heart that we decided to try to establish an intramuscular dose of atropine in the premedication which could offer comparable protection. In Series III (Table III) atropine was substituted for hyoscine in an equivalent dose-weight relationship. It can be seen that there was essentially no difference in the incidence of arrhythmias between this series and Series 
I and II, prior to the injection of atropine intravenously. It was felt, therefore, that the dose of atropine should be increased.

In Series IV and V (Tables IV and V) the dose lof atropine in the premedica tion was increased. In series IV the incidence of cardiac arrhythmias was 56 per cent and in Series V the incidence was, 48 per cent. Although the incidence of arrhythmias in the patients receiving $0.03 \mathrm{mg} . / \mathrm{kg}$. of atropine was still somewhat high, the severity of the arrhythmias was improved.

In Table VI we have tabulated the type of arrhythmias $^{-}$encountered and their distribution throughout the five series.

\section{TABLE VI}

Relative InCidence of Arirhythmias

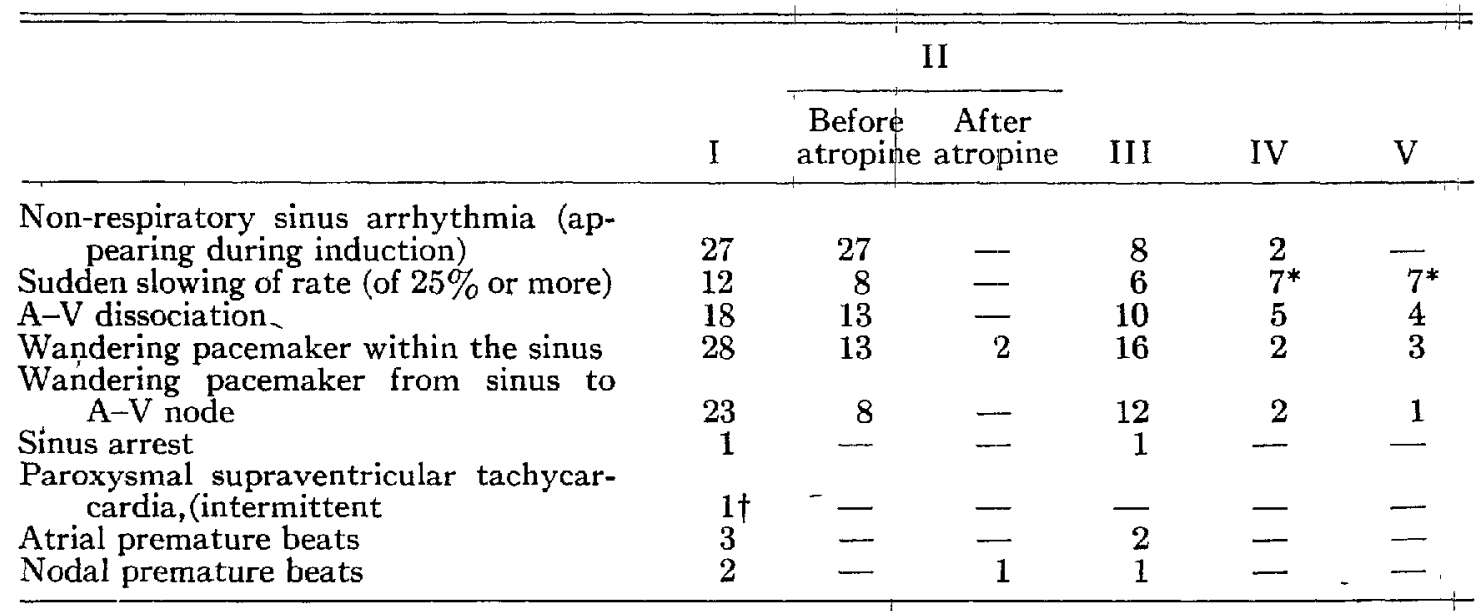

The fact that the total sum of the number of arrhythmias in each series is higher than the figures indicated in Tables $I$ to $\mathrm{V}$ is due to the fact that lalmost invariably more than one type of arrhythmia occurred in each positive case.

* Of these, only 3 cases in Series IV and 2 cases in Series $V$ had a drop in rate of 25 per cent or more. The other cases counted had drops in rate which, although not as severe, were clearly visible and were judged to be due to insufficient vagal blockade.

TThis arrhythmia represents the only instance in the entire study where a parasympatheticsympathetic interplay could be postulated.

In Series III, IV, and V the average pre-induction heart rates were comparable. Ventricular arrhythmias were conspicuously absent in the five series.

The entire study was analysed statistically by Dr. Warburton. ${ }^{*}$ Her report reads as follows:

The difference between the frequency of cardiac arrhythmias before and after the administration of intravenous atropine in Series II was highly significant, the $\chi^{2}$ having a $p$ value of less than .001 .

Because of the well-known effect of succinylcholine on cardiac rate and rhythm and the fact that the same percentage of cases in each series did not receive succinylcholine, the cases were divided into those who did and those who did not receive succinylcholine. Since the percentage of inductions performed with pentothal and with inhalation agents was approximately proportional in each group no subdivision was made on this basis.

Series I and II (before intravenous atropine) were compared with series IV and $\mathrm{V}$ combined. In the cases who received succinylcholine 44 of 56 patients (78.5\%)

\footnotetext{
Dr. Dorothy Warburton, Department of Genetics, MdGill University, Montreal.
} 
had cardiac, arrhythmias in Series I and II (before atropine) and 22 of 36 (61.1\%) had cardiac arrhythmias in Series IV and V. This difference, although not statistically significant (the $\chi^{2}$ test giving a $p$ value between .05 and .10) is very suggestive that the atropine is reducing the frequency of cardiac arrhythmias.

In the cases who did not receive succinylcholine, 16 of 19 patients (84.2\%) had cardiac arrhythmias in Series I and II (before atropine) and 4 of 14 patients (28.5\%) had arrhythmias in Series IV and V. This difference is highly significant, the $\chi^{2}$ having a $p$ value of less than .01 .

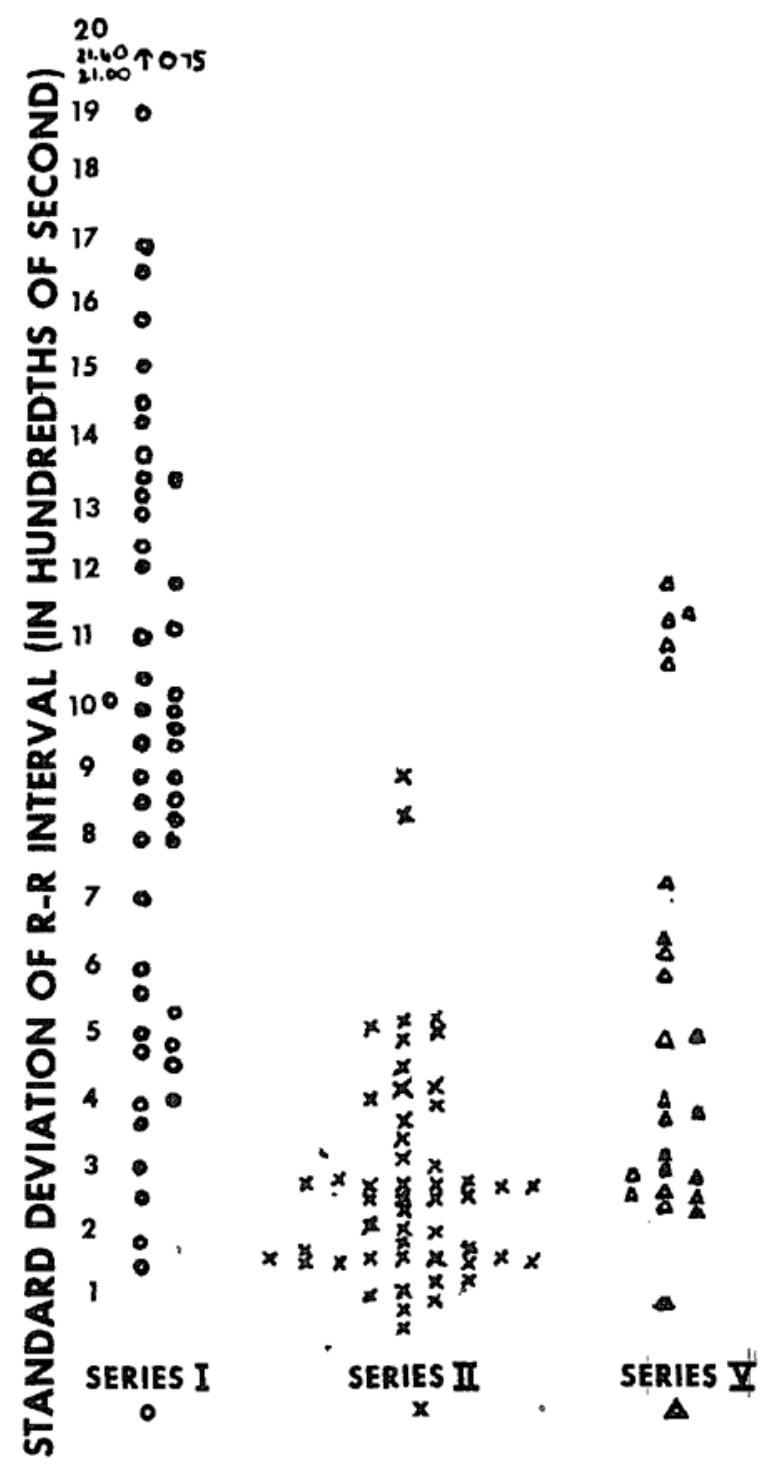

FIgURE 1. Scattergram showing standard deviations of $R-R$ interval in hundredths of a second ${ }_{n}$ in Series I, Series II after intravenous atropine, and Series V. It can be seen that intravenous atropine and to a lesser extent $0.03 \mathrm{mg}$. of atropine per $\mathrm{kg}$. of body weight intramuscularly in the premedication greatly reduce the variability of the heart rate.

The greater significance of the difference in the cases who did not receive succinylcholine, in spite of the lower numbers, implies that the administration of atropine in the premedication in Series IV and V is more effective when succinylcholine is not administered. 
The standard deviation about the mean $R-R$ interval was taken as a measure of the variability of cardiac rate. The standard deviation was calculated for each record in Series I, Series II after intravenous atropine, and Series V. These standard deviations are plotted in figure 1.

It can be seen that intravenous atropine and to a lesser extent intramuscular atropine in the dose of $0.03 \mathrm{mg} . / \mathrm{kg}$. one hour before induction have greatly reduced the variability of heart rate.

\section{Discussion}

We attributed the high incidence of vagal arrhythmias which we observed to the fact that the agents and techniques employed increased parasympathetic activity. This was substantiated by the dramatic effectiveness of intravenous atropine in abolishing these arrhythmias. In our attempt to duplicate this with an intramuscular dose in the premedication we were successful only when succinylcholine was not employed. To provide protection against succinylcholine-induced arrhythmias atropine has to be given intravenously. Higher doses of atropine given in the premedication might be equally effective.

There has been a tendency on the North American continent to use low doses of atropine in the pre-anaesthetic medication. This tendency is based on the erroneous speculation that only complete vagal inhibition, which requires toxic doses of atropine, is effective in preventing vagal arrhythmias and that excessive drying is a companion to a therapeutic effect. It has been our experience that

Case $9 / 5$

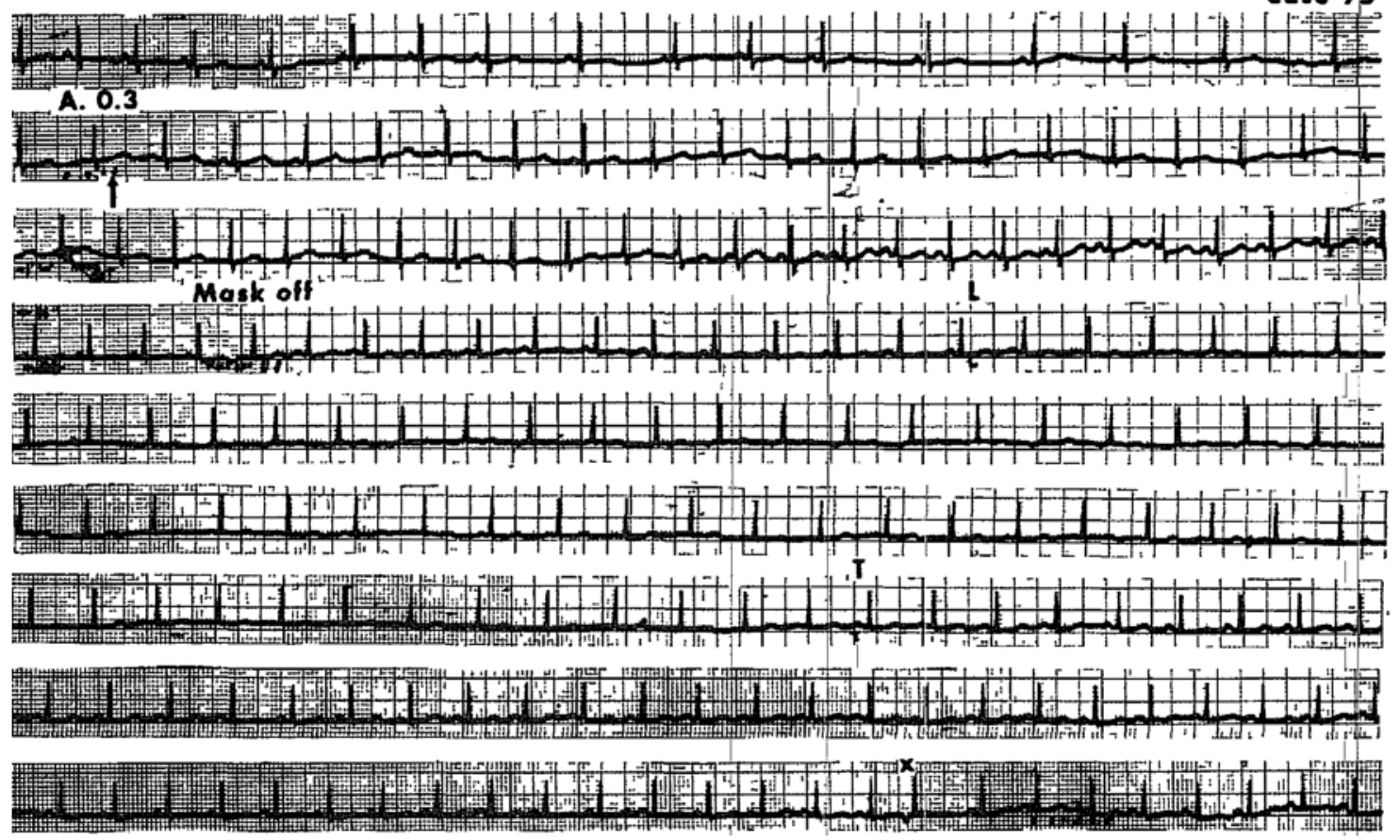

Figure 2. Tracing from one of the two patients in Series II in whom intravenous atropine was not successful in completely abolishing the pre-existing arrhythmia. After the injection of the drug (arrow) the established non-respiratory sinus arrhythmia with wandering pacemaker disappears. The pacemaker shifts first to the $\mathrm{A}-\mathrm{V}$ node but in the middle of the third row the sinus pacemaker has again taken over. From then on, throughout intubation, although the ventricular rate is perfectly regular, the atrial pacemaker is unstable. In the last row a nodal premature beat $(\mathrm{X})$ can be seen. $\mathrm{L}=$ laryngoscopy. $\mathrm{T}=$ intubation. 
complete vagal blockade is not required to protect the heart against vagal arrhythmias, since we achieved this protection with the non-toxic dose of 0.01 mg. $/ \mathrm{kg}$. intravenously. Furthermore, it has been shown ${ }^{84}$ that $1 \mathrm{mg} . / 70 \mathrm{~kg}$. of atropine intramuscularly reduces salivary secretion by only 50 per cent at its peak of action for 45 minutes. In our series, the children premedicated with $0.03 \mathrm{mg} . / \mathrm{kg}$, when specifically asked, did not complain of excessive drying, nor were they notably dry.

We consider the degrees of sinus tachycardia resulting from the administration of these doses of atropine in our study to be within the physiological ranges for effective cardiac action in children.

The children in Series V were equally co-operative with those of Series I based on the comparable numbers of children requiring rectal pentothal in each series. It appeared that this amount "of atropine given intravenously resulted in 7 of 50 patients developing transient, minor, vagal arrhythmias.

It is interesting to note that no ventricular arrhythmias were seen in these $\mathbf{1 7 5}$ continuous recordings taken during induction of anaesthesia, the administration of succinylcholine and endotracheal intubation, or the administration of atropine intravenously. This is at variance with the reported results. ${ }^{35,37-40,42,43,45}$ It is well established that halogènated hydrocarbons and cyclopropane sensitize the myocardium to circulating catecholamines, resulting in ventricular arrhythmias. High concentrations of catecholamines in the blood can be the result of a direct stimulant action of certain anaesthetic agents such as cyclopropane or ether on the adrenal medulla $a^{88}$ or due to the adrenal medullary stimulating action of carbon dioxide in high concentration. ${ }^{54}$ Administration of exogenous catecholamines may aggravate these conditions. In this series catecholamines must have been within normal limits.

Tachycardia and a rise in blood pressure have been reported during endotracheal intubation in light anaesthesia. ${ }^{87}$ Sinus tachycardia of varying degrees was frequently encountered in our study. As with the vagal arrhythmias previously described, it occurred at any time during induction. Unlike vagal arrhythmias we consider sinus tachycardia"in children to be a normal finding.

The intravenous administration of atropine may break the restraining activity of the parasympathetic system on the heart and allow unrestrained sympathetic excitation of the myocardium to develop.

\section{ConCLUSION}

Vagal arrhythmias during induction of anaesthesia in children are extremely common. They can occur at any time during induction but are more prone to occur at the time of intubation, particularly if succinylcholine has been administered intravenously.

The intravenous administration of atropine $0.01 \mathrm{mg} . / \mathrm{kg}$. prior tô the administration of succinylcholine and/or intubation is dramatically effective in abolishing and preventing these cardiac arrhythmias.

The administration of atropine $0.03 \mathrm{mg} . / \mathrm{kg}$. intramuscularly one hour prior to induction is very effective in preventing cardiac arrhythmias provided succinyl- 


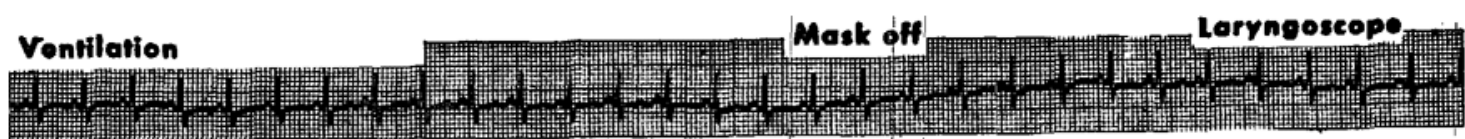

L
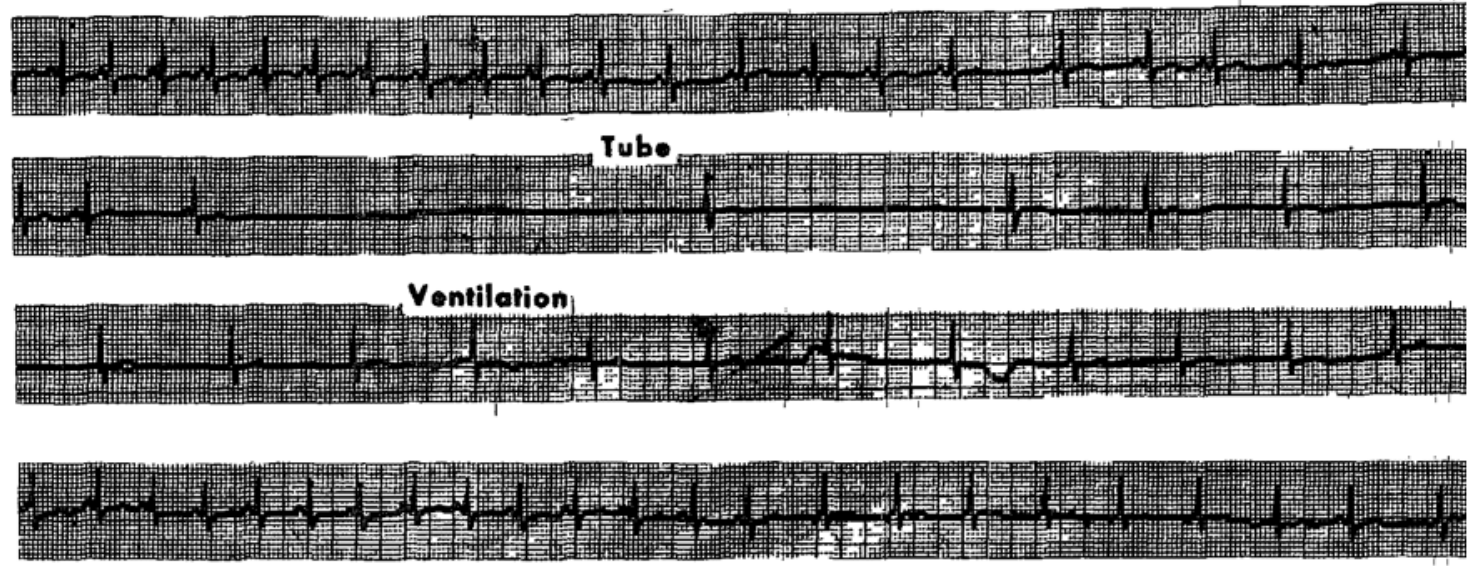

Ether and Nitrous Oxide
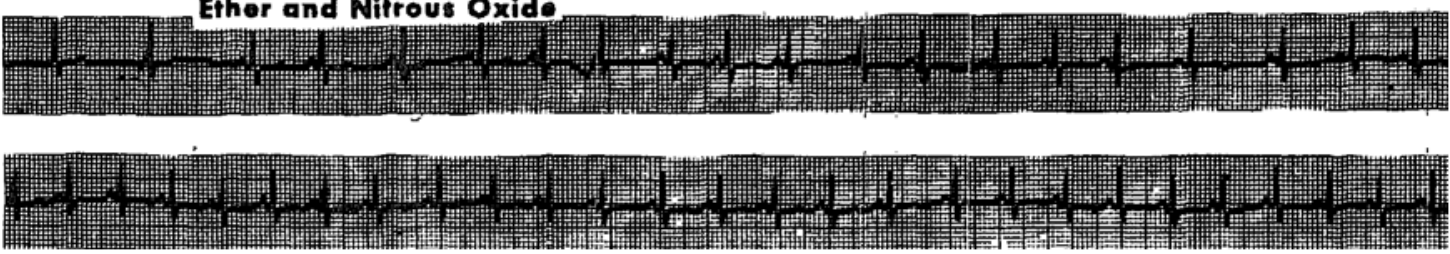

Figure 3. Sinus̃ tachycardia changes to non-respiratory arrbythmia in the middle of the second row. The first beat in the third row is nodal ( $P-R=0.08$ second) and following it there is complete electrical silence for ' 4.2 seconds, followed by a progressingly faster nodal rhythm. Sinus tachycardia ensues with some wandering of the pacemaker from the sinus to the $\mathrm{A}-\mathrm{V}$ node and final stabilization in the bottom row.

$\mathbf{L}$

T

Case 123

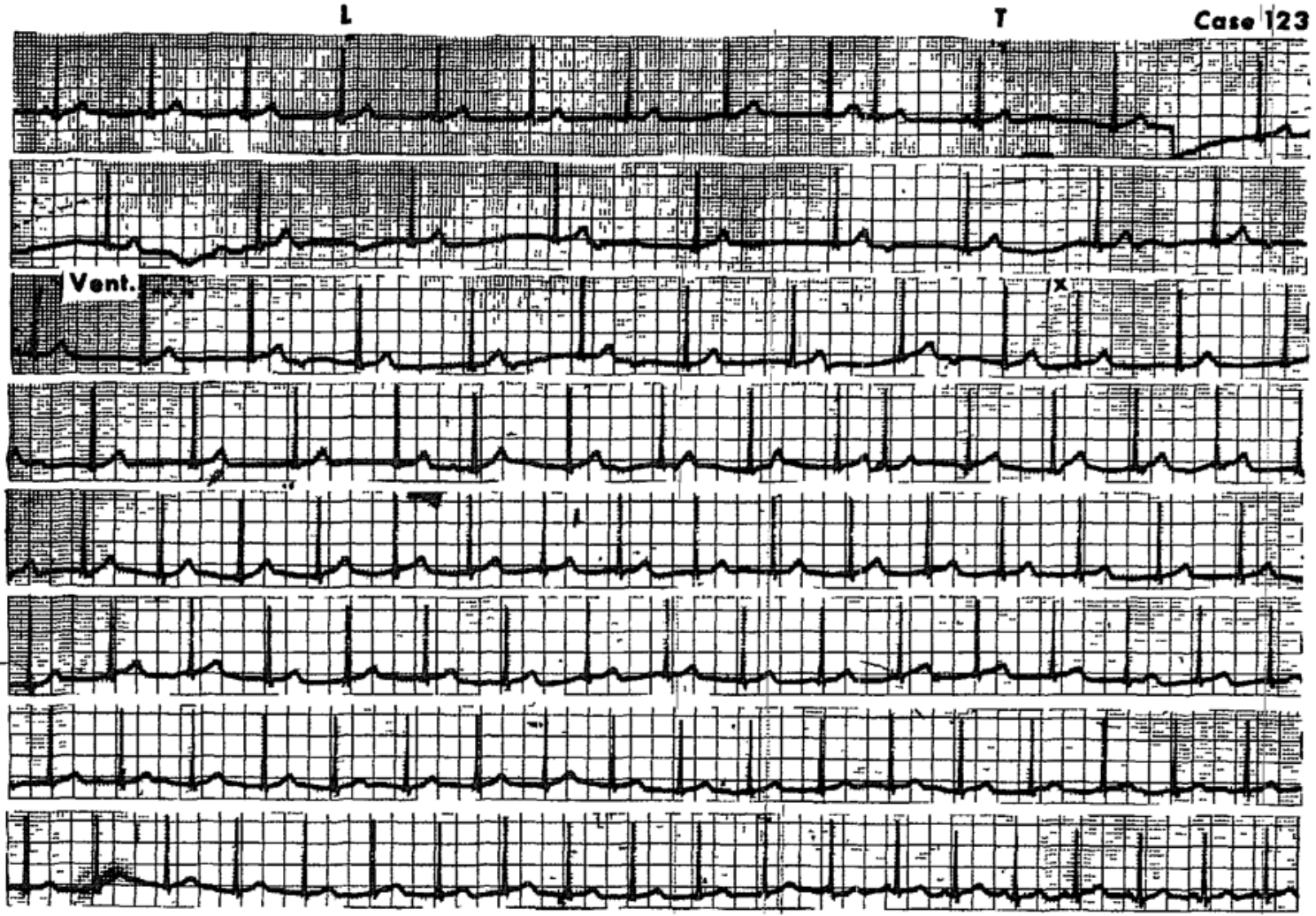

Frgure 4. In this tracing $A-V$ dissociation appears in the first row. In the second row the rhythm has become nodal with second-degree retrograde block. When the R-P interval becomes sufficiently long a reciprocal beat occurs (X). Atrial premature beats are scattered throughout, two of which (first and fourth rows) are conducted to the ventricles. 


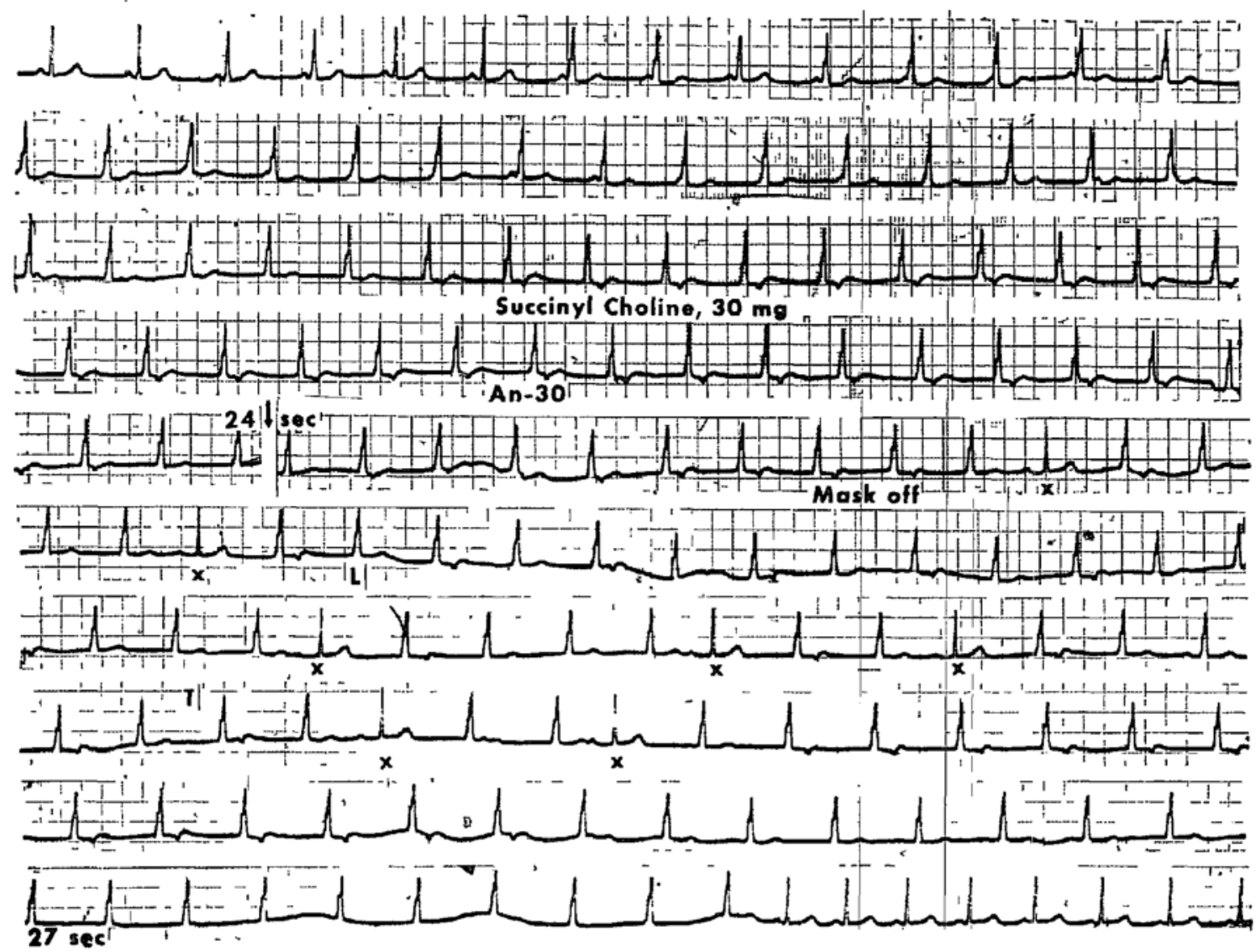

FIGURE 5. In the first row the appearance of $\mathrm{A}-\mathrm{V}$ dissociation starting with the seventh beat is manifested by the co-existence of a sinus rhythm controlling the atria (upright $\mathrm{P}$ waves) and a nodal rhythm controlling the ventricles (short $\mathrm{P}-\mathrm{R}$ interval or buried $\mathrm{P}$ waves, widening of the QRS complex). The widening of the QRS complexes is, the result of the activation of the ventricles through a different pathway (see L. Katz and A. Pick, Clinical Electrocardiography, the Arrhythmias, figure 410, Lea and Febiger, Philadelphia, 1956). The A-V dissociation is intermittent, as shown by the retrograde depolarization of the atria (negative $\mathrm{P}$ waves following the widened QRS complexes) and by occasional sinus activity capturing the ventricles with a prolonged $\mathrm{P}-\mathrm{R}$ interval and normal QRS configuration (X),

Case 97 1.7. Atropine $0.2 \mathrm{Mg}$

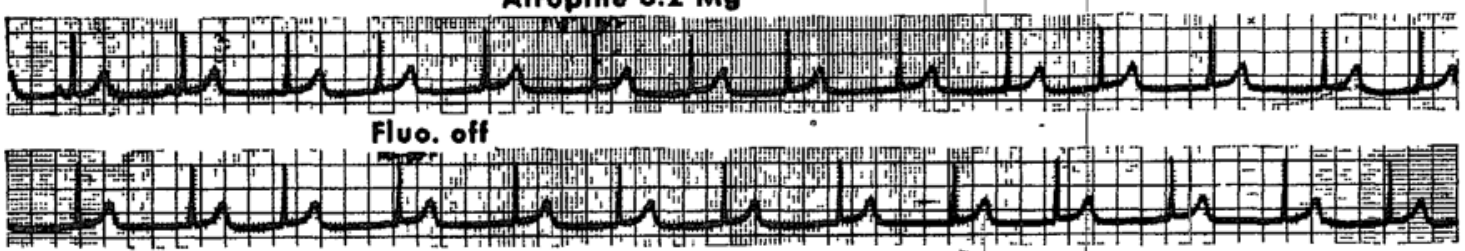

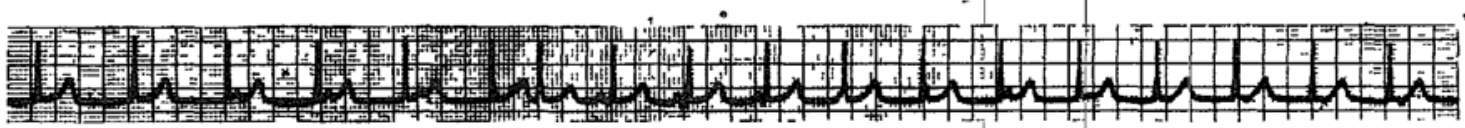

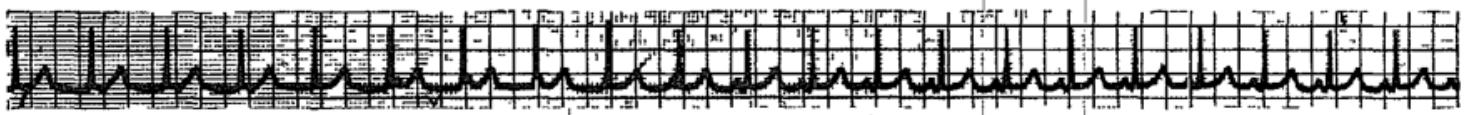

Figure 6. Wandering of the pacemaker within the sinus is clearly seen in the first row. Intravenous administration of atropine results, after a delay (rows 2 and 3 ), in A-V dissociation, evident in the fourth row. There the sinus has just been released from vagal control, $P$ waves appear following the second nodal beat but are dissociated from the nodal QRS complexes. The fourth sinus impulse succeeds in activating the ventricles but the success is short-lived and after a few beats the nodal pacemaker takes over the atrial depolarization (negative $P$ waves following the ORS complexes at the end of the fourth row and at the 


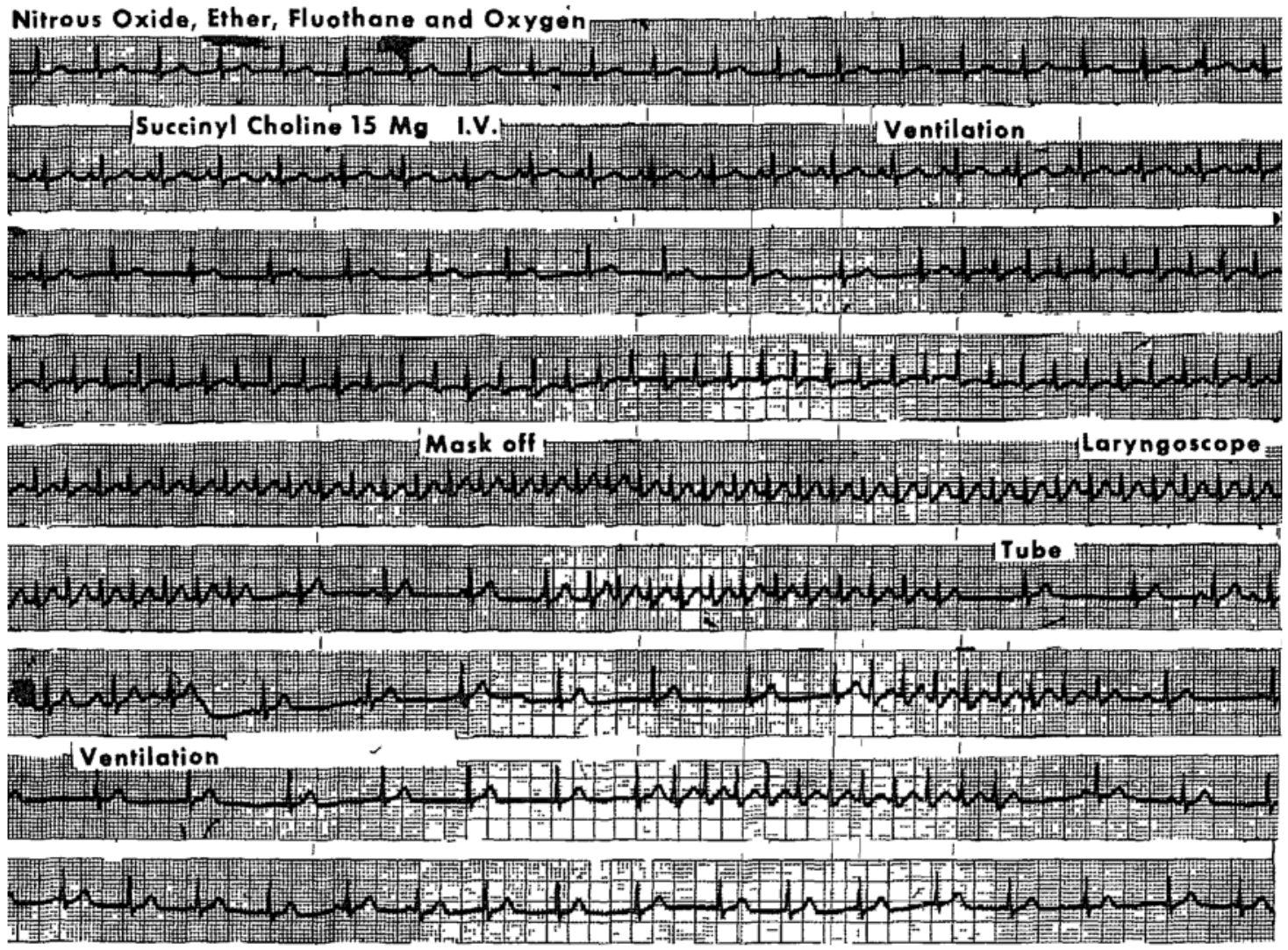

FIGURE 7. This record shows bursts of paroxysmal supraventricular tachycardia occurring in a patient whose basic rhythm alternates between sinus tachycardia and nodal rhythm. The first beats of the supraventricular tachycardia (end of third row) show electrical alternans and all the tachycardia beats are followed by a depressed RS-T segment due to the rapid rate.

Although these findings could be attributed to hyperactive vagal tone, sympathovagal interplay must be postulated.

choline is not employed. When succinylcholine is employed the incidence of arrhythmias is high but their severity diminishes. To guarantee their abolition intravenous atropine should be administered or a more effective intramuscular dose sought.

\section{RÉSUMÉ}

Au cours de l'induction de l'anesthésie chez les enfants, il arrive très fréquemment d'observer des arythmies d'origine vagalle. Elles peuvent apparaître en tout temps au cours de l'induction, mais elles ont tendance à apparaître plutôt au moment de l'intubation, surtout si l'on a administré de la succinylcholine par voie endoveineuse.

Si l'on administre, par voie endoveineuse, de l'atropine à raison de $0.01 \mathrm{mg} . / \mathrm{kg}$. avant de donner la succinylcholine et/ou de pratiquer l'intubation, on abolit ou l'on prévient, de façon radicale, les arythmies cardiaques.

A la condition de ne pas employer de succinylcholine, l'atropine, en injection intramusculaire, à raison de $0.03 \mathrm{mg} . / \mathrm{kg}$., une heure avant l'induction, est très 
efficace pour prévenir les arythmies cardiaques. Si l'on emploie la succinylcholine, la fréquence des arythmies demeure élevée mais leưr gravité diminúe.

Pour assurer l'absence d'arythmie, il faut recourir à l'administration de l'atropine par voie endoveineuse ou rechercher une dose plus efficace à donner par voie intràmusculaire.

\section{REFERENCES}

1. WAters, R. M. A Study of Morphine, Scopolamine and Atropine and Their Relation to Preoperative Medication and Pain Relief. Texas J. Med. 34: 304 (1938).

2. Rem, L. C. \& BrAce, D. E. Irritation of the Respiratory Tract and Its Reflex Action on the Heart. Surg., Gynec. Obst. 70: 157 (1940).

3. Wangeman, C. P." The Effects of Morphine, Atropine and Scopolamine on Human Subjects. Anaesthesiology 3: 24 (1942).

4. Nickerson, M. \& Smitr, S. M. Protection against Cyclopropane-Epinephrine Arrhythmias by Dibenamine and Other Agents. Anesthesiology 10: 562 (1949).

5. Nickerson, M. \& Nomaguch, G. M. Mechanism of Dibenamine Protection against Cyclopropane-Epinephrine Cardiac Arrhythmias. J. Pharmacol. \& Exper. Therap. 95: I (1949).

6. ReEs, J. G. Anaesthesia in the Newborn. Brit. Med. J. 2, 1919 (1950).

7. Leigh, M. D. \& Belton, M. K. Premedication in Pediatric Anesthesia. Anesth. \& Analg. 29: 68 (1950).

8. Johnstone, M. General Anaesthesia and Cardiac Inhibition, Brit, Heart ]. 13: 47 (1951).

9. Reim, L. C.; Stephenson, H. E.; \& Hinton. Cardiac Arrest. A.M.A. Arch. Surg. 64: 409 (1952).

10. Burstern, C. L. Pediatric Preanesthetic Preparation. Anesthesiology 14: 567 (1953).

11. Fisher, K. \& Windsor, T. Control of 'Vagal Cardiovascular Reflexes during Surgery Employing Beta-diethylaminoethyl Xanthene-9-carboxylate. Anesthesiology 14: 596 (1953).

12. KnNG, B. D.; Elder, G. D.; Proctor, D. F.; \& Dripps, R. D. Reflex Circulatory Responses to Tracheal Intubation Performed under Topical Anesthesia. Anesthesiology 15: 231 (1954).

13. Goodman, L. S. \& Gmanan, A. The Pharmacological Basis of Therapeutics. 2nd ed. New York: The MacMillan Co. (1955).

14. Stephen, C. R.; Bowers, M. A.; Nowill, W. K.; \& MArtin, R. C. Anticholinergic Drugs in Preanesthetic Medication. Anesthesiology 17: 303 (1956).

15. SMIH, R. M. Anesthesia for Infants and Children. St. Louis, Mol: The C. V. Mosby Co. (1959).

16. Leigr, M. D. \& Belton, M. K. Pediatric Anesthesiology. 2nd ed. New York: The MacMillan Co. (1960).

17. De Vault, M.; Greifenstein, F. F.F.; \& Haruis, L. G. JR. Circulatory Responses to Endotracheal Intubation in Light General Anesthesia. Effect of Atropine and Phentolamine. Anesthesiology 21: 360 (1960).

18. Bachman, L. \& Freeman, A. The Cardiac Rate and Rhythm in Infants during Induction of Anaesthesia with Cyclopropane. Atropine Versus Scopolamine as Preanaesthetic Medication. J. Pediat. 59: 922 (1961).

19. SNow, Jorn. On Chloroform and Other Anaesthetics: Their Action and Administration. London: Churchill (1858).

20. Brodie, T. G. \& Russeld, A. E. On Reflex Cardiac Inhibition. J. Physiol. 26: 92 (1900).

21. LEVx, A. G. \& LEwIs, T. Heart Irregularities Resulting from the Inhalation of Low Percentages of Chloroform Vapor and Their Relationship to Ventricular Fibrillation. Heart 3:99 (1911).

22. Levy, A. G. The Exciting Causes of Ventricular Fibrillation in Animals under Chloroform Anaesthesia. Heart 4: 319 (1913).

23. - The Genesis of Ventricular Extrasystoles under Chloroform; with Special Reference to Consecutive Ventricular Fibrillation. Heart 5: 299 (1914).

24. Brow, G. R.; LOND, C. L. H.; \& BeAtTIE, J. Irregularities of the Heart under Chloroform. Their Dependence on the Sympathetic Nervous System. J.A.M.A. 95: 715 (1930).

25. Hnx, I. G. H. The Human Heart in Anaesthesia. An Electrocardiographic Study. Edinburgh Med. J. 39: 533 (1932). 
26. Downs, T. M. The Carotid Sinus as an Etiological Factor in Sudden Anesthetic Death. Ann. Surg. 99: 974 (1934).

27. Kuntz, C. M.; Bennetr, J. H.; \& Shaptro, H. H. Electrocardiographic Studies during Surgical Anesthesia. J.A.M.A. 106:1434 (1936).

28. Orth, O. S.; Leigh, M. D.; Mexlish, C. H.; \& Stútzman, J. W. Action of Sympathomimetic Amines in Cyclopropane Ether and Chloroform Anesthesia. J. Pharmacol. \& Exper. Therap. 67: 1 (1939).

29. MeEk, W. J.; Hathaway, H. R.; \& Onth, O. S. Effects of Ether, Chloroform and Cyclopropane on Cardiac Automaticity. J. Pharmacol. \& Exp. Therap. 62: 240 (1939).

30. Axten, C. R. The Production of Ventricular Tachycardia by Adrenaline in Cyclopropane Anesthesia. Anesthesiology 1: 158 (1940).

31. MEEK, W. J. Cardiac Automatioity and Response to Blood Pressure (Raising Agents during Inhalation Anesthesia. Physiol. Rev. 2I: 324 (1941).

32. Waters, R. M. Trichloroethylene Anesthesia and Cardiac Rhythm. Anesthesiology 4: I (1943).

33. Lee, W. V.; Orth, O. S.; Wangeman, C. P.; \& Meek, W. J. The Mechanism of Production of Spontaneous Cardiac Irregularities with High Concentrations of Cyclopropane. Anesthesiology 4: 487 (1943).

34. Robrins, B. H. The Effect of Ether, Divinyl Ether and Cyclopropane Anesthesia upon the Heart Rate and Rhythm and Blood Pressure during Normal Respiratory Activity and during Artificial Respiration. after Respiratory Arrest J. Pharmacol. \& Exper. Therap. 85: 192 (1945).

35. Burstenn, C. L.; Plazza, T. L.; Kapp, L. A.; \& Rovennsttne, E. A. Cardiocirculatory Disturbances during Intrathoracic Surgery. Surgery 25: 36 (1949). ।

36. Johnstone, M. Cyclopropane Anaesthesia and Ventricular Arrhythmias. Brit. Heart J. 12: 239 (1950).

37. Bunstein, C. L.; Lopinto, F. J.; \& Newman, W. Electrocardiographic Studies during Endotracheal Intubation. Effect during Usual Routine Techniques. Anesthesiology 11: 224 (1950).

38. Burstein, C.: L.; Woloshin, G.; \& Newman, W. Electrocardiographic Studies during Endotracheal Intubation. II. Effects during General Anesthesìa and Intravenous Procaine. Anesthesiology 11: 299 (1950).

39. Burstein, C. L.; Zaino, C.; \& Newman, W. Eleptrocardiographic Studies during Endotracheal Intubation. III. Effects during General Anesthesia and Intravenous Diethylaminoethanol. Anesthesiology 12: 411 (1951).

40. Peters, N. S.; Newman, W.; \& Burstein, C. L. Electrocardiographic Studies during Endotracheal Intubation. IV. Effects during Cyclopropane Anesthesia with Intravenỡus Procaine Amide. Anesthesiology 12: 673 ( 1951 f).

41. Jornstone, M. The Cardiology of Anesthesia. Anesth. \& Analg. 31: 325 (1952).

42. Arcuri, R. A.; Newman, W.; \& Burstein, C. L. Electrocardiographic Studies during Endotracheal Intubation. V. Effects during General Anesthesia and Hexylcaine HCl Topical Spray. Anesthesiology 14: 46 (1953).

43. Rosner, S.; Newman, W.; \& Bunstens, C! L. Electrocardiographic Studies during Endotracheal Intubation. VI. Effects during Anesthesia with Thiopental Sodium Combined with Muscle Relaxant. Anesthesiology 14:591 (1953).

44. Jomnstone, M. Some Mechanisms of Cardiac Arrest during Anaesthesia. Brit. J. Anaesth. 27: 566 (1955).

45. Horton, J. Electrocardiographic Findings during Laryngoscopy and Endotracheal Intubation. Brit. J. Anaesth. 27:326 (1955).

46. Jacoby, J.; Ziegler, C.; Hamerberg, W.; Mogg, A., Klassen, K.; \& Flory, F. Cardiac Arrhythmia: Effect of Vagal Stimulation and Hypoxia. Anesthesiology 16: 1004 (1955).

47. Rosson, G. J. \& Sheridan, C. A. Preliminary Investigation with Fluothane. Anesth. \& Analg. 36: 62 (1957).

48. MHLAR, R. R.; Gir.BERT, R. G. B.; \& BRINDle, G. F. Ventricular Tachycardia during Halothane Anaesthesia. Anaesthesia 13: 164 (1958).

49. DundeE, J. W. \& Black, G. W. Review of the Cardiovascular Effects of Halothane.

Anaesthesia 15: 349 (1960).

50. Craythorne, N. W. B.; Turndore, H.; \& Dripps, R. D. Changes in Pulse Rate and Rhythm Associated with the Use of Succinylcholine in Anesthetized Children. Anesthesiology 21: 465 (1960).

51. Johnstone, M. \& Nisbet, H. I. A. Ventricular Arrhythmia during Halothane Anaesthesia. Brit. J. Anaesth. 33: 9 (1961). 
52. Whliams, C. H.; Deutsch, S.; Linde, H. W.; Bullough, G, W/; \& Dripps, R. D. Effects of Succinylcholine on Cardiac Rate, Rhythm and Blood Pressure in Anaesthetized Man. Anesthesiology 22: 947 (1961).

53. McINTYRE, J. W. R. Succinylcholine-Induced Bradycardia with Reference to Methoxyflurane Anaesthesia. Canad. Anaesth. Soc. J. 9: 408 (1962).

54. MILlar, R. A. \& Morris, M. E. Sympatho-adrenal Responses during General Anaesthesia in the Dog and Man. Canad. Anaesth. Soc. J. 8: 357 (1961).

55. LewIS, T. The Effect of Vagal Stimulation upon Atrioventricular Rhythm. Heart 5: 247 (1914).

56. Anrep, G. V. \& Segall, H. N. The Central and Reflex Regulation of the Heart Rate. J. Physiol. 61: 215 (1916).

57. Rycant, P. La Transmission humorale de l'action des nerfs cardiaques de Loewi chez le mammifere. Compt. rend. soc. biol. 96: 204 (1927).

58. WEDD, A. M. Standstill of Vagal Origin. Heart J. 5: 493 (1930).

59. HrL, I. G. Stimulation of the Vagus. Quart. J. Exper. Physiol. 22 : 79 (1932).

60. Weiss, S. \& Baker, J. P. Carotid Sinus Reflex in Health and Disease; Its Role in Causation of Fainting and Convulsions. Medicine 12: 297 (1933).

61, Weiss, S. \& Ferris, E. B. Jr. Adams-Stokes Syndrome with Transient| Complete Heart Block of Vago-Vagal Reflex Origin. Am. Arch. Intern. Med. 54: 931 (1934).

62. Hodes, R. Exercise in Sympathectomized Cat. Am. J. Physiol. 126: 171 (1939).

63. Brouna, L. \& Nowak, S. J. G. Role of the Vagus in the Cardio-Accelerator Action in Emotion in Sympathectomized Dogs. J. Physiol. 95: 454 (1939).

64. - Role of the Vagus in the Cardio-Accelerator Action of Atropine in Sympathectomized Dogs! J. Physiol. 95: 439 (1939).

65. Rem, L. C. \& BrACE, D. E. Irritation of the Respiratory Tract and Its Reflex Effect upon the Heart Surg., Gynec. \& Obstet. 70: 157 (1940).

66. Cohn, A. E. \& Macleon, A. G. The Effect of Acetylcholine on the Mammalian Heart. Am. Heart J. 21: 356 (1941).

67. Bond, D. D. Sympathetic and Vagal Interaction in Emotional Responses of the Heart. Am. J. Physiol. 138: 468 (1943).

68. Burstein, C. L.; Martin, S. J.; \& Rovenstine, E. A. Threshold Variations to Vagus Nerve Stimulation. J. Thor, Surg. 13: 49 (1944).

69. Scherf, D. Cardiac Reflexes Originating in the Respiratory Tract. New York J. Med. 45: 1647 ( 1945 ).

70. Holmes, J. H. \& WeILL, D. R. JR. Incomplete Heart Block Produced by Changes in Posture. Am. Heart J. 30: 291 (1945).

71. Greiner, T. H. \& Garb, S. The Influence of Drugs on the Irritability and Automaticity of Heart Muscle J. Pharmacol. \& Exper. Therap. 98: 215 (1950).

72. ScotT, J. C. \& REED, E. A. Electrocardiographic Effects of Reflex Vagal Stimulation. Am. J. Physiol. 167: 441 (1951).

73. Hoffman, B. F. \& Sucking, E. E. Cardiac Cellular Potential, Effect of Vagal Stimulation and Acetylcholine. Amer. J. Physiol. 173: 312 (1953).

74. Burs, J. H. Acetylcholine and the Heart Beat. Lancet: i, 1161 (1953).

75. Rushmer, R. F. Autonomic Balance in Cardiac Control. Am. J. ${ }^{\text {P }}$, Aysiol. 192: 631 (1958).

76. Sloan, H. E. The Vagus Nerve in Cardiac Arrest. Surg., Gynec. \& Obstet. 91: 259 (1959).

77. Dr Palma, J. B. Pharmacology of Drugs used in Cardiac Arrhythmias and Disturbances in Conduction. Progr. Cardiovasc. Dis. 2 (1960).

78. Veda, L.; Fukushma, K.; Ballinge, C. M.; \& Loehning, R. W. Epinephrine Induced Arrhythmias: Effect of Carbon Dioxide and Acid-Base Changes. Anesthesiology 23: 343 (1962).

79. WILson, F. N. Production of A-V Rhythm in Man after Administration of Atropine. A.M.A. Arch. Intern. Med. 16: 989 (1915).

80. Alexander, E. Atropine Poisoning. New Engl. J. Med. 234: 258 (1946).

81. Joos, H. A. Atropine Intoxication in Infancy. Am. J. Dis. Child 79: 855 (1950),

82. Pooler, H. E. Atropine, Neostigmine and Sudden Deaths. Anaesthesia 12: 198 (1957).

83. Morton, H. J. V. \& Thomas, E. T. Effect of Atropine on the Heart Rate. Lancet ii, 1313 (1958).

84. Stewart, W. C. \& Currue, H. The Relationship between the Dosage of Atropine and the Effects of Reflex Parotid Secretion and Heart Rate in Man. Canad. M.A.J. 85: 180 (1961). 
85. Jones, R. E.; Deutsch, S.; \& TuRndoRF, H. Effects of Atropine on Cardiac Rhythm, in Conscious and Anesthetized Man. Anesthesiology 22: 67 (1961).

86. CoLón-Yordán, E. \& JIMÉNEZ-VÉLEz, J. L. Effects of Intravenous Atropine and Scopolamine during Cyclopropane-Succinylchóline Anesthesia. Anesthesiology 23: 333 (1962).

87. King, B. D.; Harris, L. C.; Greifenstein, F. E.; Elder, J. D.; \& Drupps, R. D.' Reflex Circulatory Responses to Direct Laryngoscopy and Tracheal Intubation Performed during General Anesthesia. Anesthesiology 12: 556 (1951).

88. Price, H. L.; Lurie, A. A.; Jones, R. E.; Price, M $\nmid$ L.; \& Linde, H. W. Cyclopropan'e Anesthesia, II Epinephrine and Nurepinephrine in Initiation of Ventricular Arrhythmias by Carbon Dioxide Inhalation. Anesthesiology 19: 618 (1958). 